\title{
Problematic Smartphone Usage and Subjective and Psychological Well-Being
}

\author{
Sharon Horwood, Jeromy Anglim
}

\begin{abstract}
Despite a growing awareness that problematic usage of smartphones is becoming a significant public health issue, there is limited research on how problematic smartphone usage relates to the humanistic concepts of well-being, particularly those captured in Ryff's six psychological well-being dimensions: positive relations, autonomy, environmental mastery, personal growth, purpose in life, selfacceptance. The current study aimed to provide a comprehensive assessment of the relationship between general and problematic smartphone usage and subjective wellbeing and psychological well-being using long-form, theoretically grounded measures. Australian adults ( $n=539,79 \%$ female; age in years $\mathrm{M}=25.1, \mathrm{SD}=7.8)$ completed Diener's Satisfaction with Life Scale, the PANAS, and Ryff's 84-item measure of psychological well-being. Results showed that problematic smartphone usage was correlated with lower well-being on almost all scales. In particular, negative affect, autonomy, and environmental mastery had the largest negative correlations with problematic smartphone usage. Given the stable and dispositional nature of well-being, it seems likely that much of the relationship is driven by a common underlying tendency to experience anxiety, negative emotions, and a lack of control, combined with a tendency to engage in maladaptive coping and compulsive behavior.

Keywords: problematic smartphone usage, subjective well-being, psychological well-being, fear of missing out, satisfaction with life
\end{abstract}

\section{Introduction}

Despite the many benefits offered by smartphones, including social connectedness, safety, task efficiencies, and entertainment, many individuals report that their usage has become excessive to the point where it has led to negative consequences in their daily life. For example, in a 2017 survey of adults, 54\% reported being occupied on their smartphone when they should be doing other things, and it caused problems, 34\% reported losing sleep due to the time they spend on their smartphone, and $65 \%$ reported being engaged on their smartphone for longer periods of time than intended (Horwood \& Anglim, 2018). This raises the question of whether

${ }^{1}$ Horwood, S. \& Anglim, J. (2019). Problematic Smartphone Usage and Subjective and Psychological Well-Being. Computers in Human Behavior. https://doi.org/10.1016/j.chb.2019.02.028

Please see the doi to publisher's copy of record and check for updated volume and page numbers. Sharon Horwood, School of Psychology, Deakin University, Geelong, Australia; Jeromy Anglim, School of Psychology, Deakin University, Geelong, Australia; Correspondence concerning this article should be addressed to Sharon Horwood, School of Psychology, Deakin University, Locked Bag 20000, Geelong, 3220 Australia. Email: sharon.horwood@deakin.edu.au 
smartphone usage is impacting people's well-being, and, if so, which aspects of wellbeing are affected. While the traditional focus on subjective well-being (SWB, Diener, 2009a) - a composite of positive affect, low negative affect, and satisfaction with life - provides the dominant framework for examining this relationship, the humanistic concepts captured in the construct of psychological well-being (PWB, Ryff \& Keyes, 1995) provide a complimentary and more complete perspective. In particular, reductions in PWB dimensions such as autonomy, personal growth, social relations, and purpose in life may be more proximal consequences of excessive and compulsive smartphone usage.

Although initial research examining the relationship between smartphone usage and well-being has been informative (e.g. Chan, 2018; Chen \& Li, 2017; David, Roberts, \& Christenson, 2018; Hughes \& Burke, 2018; Kumcagiz \& Gündüz, 2016; Li, Lepp, \& Barkley, 2015; Park \& Lee, 2012; Rotondi, Stanca, \& Tomasuolo, 2017), there are several limitations. Specifically, research has not provided a comprehensive mapping of general and problematic smartphone usage onto SWB and PWB. Studies ostensibly measuring SWB have often relied on single-item measures of life satisfaction or not measured positive and negative affect. Studies ostensibly measuring PWB have often simply used the term PWB as a synonym for well-being. Other studies have used the short-form 8-item Diener (2010) measure of 'psychological flourishing', which does not provide a measure of the six components of PWB identified by Ryff. Importantly, the main benefit of Ryff's conceptualization of PWB is the measurement of these six components. Thus, the current study aimed to provide the first comprehensive mapping of general and problematic smartphone usage onto subjective and psychological well-being. To achieve this aim, a survey was administered to a large sample of Australian adults that included comprehensive and long-form measures of SWB and PWB.

\subsection{Problematic Smartphone Usage}

Problematic smartphone usage has been defined as compulsive usage that leads to impaired daily functioning in terms of productivity, social relationships, physical health, or emotional well-being (Horwood \& Anglim, 2018). Despite the various benefits of smartphones, many studies have obtained correlations between problematic usage and stress (e.g., Cao, Masood, Luqman, \& Ali, 2018; Kim, Min, Min, Lee, \& Yoo, 2018; Kuang-Tsan \& Fu-Yuan, 2017; Samaha \& Hawi, 2016; Van Deursen, Bolle, Hegner, \& Kommers, 2015). The notion that smartphones can cause users to become stressed, overwhelmed, and exhausted has been termed 'technostress' (Ayyagari, Grover, \& Purvis, 2011; Lee, Chang, Lin, \& Cheng, 2014; Maier, Laumer, Weinert, \& Weitzel, 2015; Tarafdar, 2017), or, in some cases, 'techno-exhaustion' (Cao et al., 2018). The term 'technostress' was originally used to describe workplace productivity decrements that could be attributed to the sustained efforts required by employees to remain proficient in changing information and communication technology domains (Ragu-Nathan, Tarafdar, Ragu-Nathan, \& Tu, 2008; Tarafdar, Tu, Ragu-Nathan, \& Ragu-Nathan, 2007), however more recently the idea of technologyinduced stress has been extended to users of smartphone technology. One explanation for the experience of technostress is that continuous access to, and demand for attention from, social networking sites, supply of news and information, work activities, and various forms of entertainment result in cognitive-emotional pre- 
occupation with the agent of delivery, the smartphone (Cao et al., 2018; Lee et al., 2014). Another explanation for the development of technostress is that users feel that their smartphone has become an intrusion in their daily life (Ayyagari et al., 2011). Furthermore, some users engage in compulsive usage of their smartphone, akin to a behavioral addiction, as a result of the ease with which immediate gratification can be obtained from the device (Cao et al., 2018; Lee et al., 2014).

\subsection{Subjective and Psychological Well-Being}

Subjective well-being (SWB) has been influentially defined in terms of a tripartite model consisting of high positive affect, low negative affect, and satisfaction with life (Diener, 2009a, 2009b; Diener, Lucas, \& Oishi, 2018; Diener \& Ryan, 2009; Tov \& Diener, 2013). Importantly, SWB does not prescribe what should make people experience positive or negative emotions, nor does it prescribe what makes for a good life. As a complementary perspective, the construct of psychological well-being (PWB) has been proposed. It builds on the definition of subjective well-being by incorporating various aspects of human potential, and the ways in which individuals cope with existential challenges in life (Houben, Van Den Noortgate, \& Kuppens, 2015; Keyes, Shmotkin, \& Ryff, 2002b). Psychological well-being was developed primarily in response to criticisms that suggested SWB did not encompasses a broad enough range of humanistic factors that give meaning to the concept of 'wellness' (Ryan \& Deci, 2001; Ryff \& Keyes, 1995). The most widely adopted framework for conceptualizing PWB was developed by Ryff (1989) and consists of six dimensions: self-acceptance, positive relations with others, autonomy, environmental mastery, purpose in life, and personal growth.

\subsection{Smartphone Usage and Well-Being}

Initial research has found that problematic smartphone usage is negatively correlated with various conceptions of well-being including subjective well-being (e.g. Chan, 2018; Chen \& Li, 2017; David et al., 2018; Hughes \& Burke, 2018; Kumcagiz \& Gündüz, 2016; Li et al., 2015; Park \& Lee, 2012; Rotondi et al., 2017), mental health (e.g. Hughes \& Burke, 2018; Lapierre \& Lewis, 2016; Li et al., 2015; Rotondi et al., 2017; Toda, Ezoe, Mure, \& Takeshita, 2016), and mood or anxiety disorders (e.g. Alhassan et al., 2018; Arpaci, Baloğlu, Özteke Kozan, \& Kesici, 2017; Elhai, Levine, Dvorak, \& Hall, 2016, 2017; Gao, Xiang, Zhang, Zhang, \& Mei, 2017; Han, Kim, \& Kim, 2017; Hussain, Griffiths, \& Sheffield, 2017; Kim \& Koh, 2018; Kim, Joo, Han, Kim, \& Choi, 2018; Kim, Jang, Lee, Lee, \& Kim, 2018). While some have interpreted this to indicate that smartphones are causing lower levels of well-being, it is important to consider that well-being and related dispositional factors may also cause perceived and actual problematic smartphone usage. For example, a number of studies have identified trait neuroticism as a strong predictor of problematic smartphone usage (Gao et al., 2017; Horwood \& Anglim, 2018; Kayiş et al., 2016).

Nonetheless, there are potential explanations for how problematic smartphone usage may influence well-being. Problematic or compulsive smartphone usage can have negative impacts on users' social relationships. One element of problematic smartphone usage is known as 'phubbing', short for 'phone snubbing', the act of ignoring social others in favor of using a smartphone. Such usage is associated with poorer romantic relationship satisfaction in a number of studies (Chotpitayasunondh \& Douglas, 2016; Lapierre \& Lewis, 2016; Rotondi et al., 2017). Although the 
mechanisms that lead to problematic smartphone usage are not yet clear, there is evidence to suggest that characteristics of users may predict who is more likely to develop a problematic relationship with their phone.

It is also important to consider what kinds of smartphone usage are related to SWB and PWB. In particular, many aspects of phone usage are functional and facilitate humanistic pathways to well-being such as social connectedness, achieving productive goals, and being safe. For example, some studies have reported positive relationships between particular smartphone uses and SWB (e.g. facilitating new friendships or social bonding, Chen \& Li, 2017; reading ebooks, David et al., 2018). In contrast, excessive usage that leads to impairments in daily functioning seems to be the common thread among studies examining the relationship between smartphones and well-being. Habitual smartphone usage has been found to predict problematic smartphone usage (Horwood \& Anglim, 2018), thus it may be reasonable to expect that habitual usage will also be associated with reduced well-being. Similarly, given that excessive smartphone use has been associated with decreased social and romantic relationship satisfaction (Chotpitayasunondh \& Douglas, 2016; Lapierre \& Lewis, 2016), it could be supposed that relationship decrements may contribute to reduced well-being.

Thus, we aim to explore two specific questions with respect to problematic smartphone usage and well-being. First, we examine the relationship between problematic smartphone use and well-being. Second, given the emerging evidence of smartphone-related technostress, relationship stress, and disruptions in daily living we examine whether specific aspects of wellbeing are more likely to be related to problematic smartphone use than others. Specifically, we aim to investigate the strength of the relationships between problematic smartphone usage and PWB subscales.

\section{Method}

\subsection{Open Practices Statement}

Data, scripts, materials, and supplementary analyses are available at https://osf.io/4kc9g

\subsection{Participants and Procedure}

The sample were drawn from an undergraduate psychology unit at an Australian University. Data collection took place across two cohorts from mid to late 2017. Each student who completed the survey was able to have their personality data returned, to informed coursework in the unit. As students were able to receive personally relevant feedback, motivation to complete the survey and attend appropriately to the items was high. Prior to completing the surveys, students were asked to indicate whether they consented to their anonymized data being added to a larger pool of data to be used for research purposes. Data from students who did not consent were not included in the present analyses. In a single sitting, participants completed measures of subjective well-being, psychological well-being, and smartphone usage, along with other measures that were not the focus of the current study (i.e., personality). Data on personality and smartphone usage from the first of the two cohorts were reported in Horwood and Anglim (2018).

The final cleaned sample consisted of 539 participants $(79 \%$ female; age in years $\mathrm{M}=25.1, \mathrm{SD}=7.8$, range: 18 to 65 ). This was based on an initial sample of 578 , 
of which 39 were removed. These participants were removed for one or more of the following reasons: (a) not completing the well-being measures $(n=11)$, (b) not providing age and gender $(n=19)$, (c) not completing smartphone measures $(n=11)$, (d) problematic responding to the PWB measure indicated by using fewer than 4 of the response options across all PWB items $(\mathrm{n}=11),(\mathrm{e})$ reporting not using a smartphone $(n=6)$, and (f) completing the survey so quickly that they may not have had time to read the items (i.e., less than 15 minutes) $(n=2)$. To examine outliers, analyses were conducted on the 13 primary scales ( 9 well-being and 4 smartphone) on the retained data. Mahalanobis distance was calculated and bivariate scatterplots were examined. No problematic cases were identified. The largest Mahalanobis values were generally associated with either low levels of smartphone usage or low levels of well-being. This data was retained because it most likely constitutes valid responses and it is variance in well-being and usage that the project seeks to model.

The present sample size provides the following power to identify given true correlations: $80 \%$ power for .12 correlations, $90 \%$ power for .14 correlations, and $99 \%$ power for .18 correlations. Given the emphasis on identifying patterns in correlations, the present sample size enabled suitably small standard errors for correlations. Specifically, the standard error was no larger than .04, and was substantially smaller for larger correlations typical of this research domain (e.g., standard error of .027 for $r=.60)$.

\subsection{Materials}

\subsubsection{Problematic Smartphone Usage}

Problematic smartphone usage was measured using the 27-item Mobile Phone Problem Usage Scale (Bianchi \& Phillips, 2005). For the purposes of calculating an overall scale score, we excluded 8 items and instead took the mean of the 19 remaining items as set out in Horwood and Anglim (2018). We adopted a more traditional 5point scale where $1=$ strongly disagree, $2=$ disagree, $3=$ neither agree nor disagree, 4 $=$ agree, and $5=$ strongly agree. Scale score was the mean of items.

\subsubsection{Smartphone Usage Scale}

The smartphone usage measure from Van Deursen et al. (2015) included 6 items measuring habitual smartphone usage, 7 items measuring what we label entertainment usage (and which they label process usage), and 5 items measuring what we label communication usage (and which they label social usage). We prefer the label of communication usage because the items pertain to making phone calls and sending text messages rather than being concerned with social media. Items were rated on a 5 point scale from $1=$ strongly disagree to $5=$ strongly agree. Scale scores were the mean of constituent items.

\subsection{Satisfaction with Life Scale}

Satisfaction with Life was measured using Diener's 5 item Satisfaction with Life scale (Diener, Emmons, Larsen, \& Griffin, 1985). This is arguably the most well established satisfaction with life scale. Items were rated on a 7 -point scale $(1=$ strongly disagree, $2=$ disagree, $3=$ slightly disagree, $4=$ neither agree nor disagree, $5=$ slightly agree, $6=$ agree, $7=$ strongly agree). The scale score was the mean of items.

\subsubsection{Positive and Negative Affectivity Schedule (PANAS)}

The frequency of positive and negative affect was measured using the PANAS (Watson, Clark, \& Tellegen, 1988). In the current study, participants were asked about 
how frequently they had experienced the emotions in "the past few weeks". This included 10 positive and 10 negative items that each concerned a different emotion, and were rated on a 5-point scale $(1=$ very slightly or not at all, $2=$ a little, $3=$ moderately, $4=$ quite a bit, $5=$ extremely). Scales were scored as the mean of constituent items.

\subsubsection{Psychological Well-Being}

Ryff's (1989) 84-item measure of psychological well-being (PWB) was used to measure the six proposed dimensions of PWB. Items were rated on a 6-point scale $(1=$ strongly disagree, 2 = disagree somewhat, $3=$ disagree slightly, $4=$ agree slightly, 5 = agree somewhat, $6=$ strongly agree). The scale consisted of positively and negatively worded items, and scale scores were the mean after item reversal.

\subsection{Data Analytic Approach}

In order to examine our research questions, we first examined bivariate correlations between well-being and smartphone usage. We then conducted regression analyses predicting well-being variable from problematic and general smartphone usage. Regression models also included age and gender (male coded 0; female coded 1) as control variables.

\section{Results}

Table 1 presents descriptive statistics, Cronbach's alpha reliability, and scale intercorrelations. All scales exhibited good internal consistency reliability. Indicative that all well-being variables are related to a general well-being factor, all well-being scales exhibited positive correlations if negative affect is reversed. With regards to demographics, older participants reported higher levels on all psychological wellbeing scales and lower levels of general and problematic smartphone usage. Although gender differences were small, females reported higher well-being on a few scales (e.g., personal growth, purpose in life) and slightly greater levels of general and problematic usage.

Several important patterns emerged when examining the correlations between smartphone usage and well-being. In general, problematic smartphone usage was negatively correlated with well-being scales. Correlations were strongest with autonomy (-), environmental mastery (-) and negative affect $(+)$. Interestingly, the correlation with satisfaction with life was close to zero. In general, habitual usage was relatively unrelated, communication usage (i.e. calls and text messages) showed some positive correlations, and entertainment usage generally showed negative correlations with well-being scales. Several notable correlations between usage and well-being stand out, including: both entertainment and habitual usage with autonomy (-), and communication usage and positive relations with others $(+)$.

Table 2 presents regression coefficients and variance explained for regression models predicting each well-being variable from gender, age, the three smartphone usage scales, and problematic smartphone usage. Overall, personal growth, environmental mastery, and autonomy were best predicted. Satisfaction with life was the least well predicted. In general, age predicted higher levels of PWB and negative affect but not positive affect and satisfaction with life. Effects of gender were small. Problematic usage was a strong predictor of lower levels of well-being. In general, although all smartphone variables were intercorrelated, it was entertainment usage, as opposed to habitual or communication usage that predicted lower well-being. 
Communication usage predicted greater well-being, and was a particularly strong predictor of positive relations. Interestingly, when controlling for other factors, standardized betas for habitual usage were often larger and more positive predictors of well-being than is implied by the zero-order correlations (e.g., habitual usage with personal growth is a .07 correlation and a .31 standardized beta).

\section{Discussion}

The current study aimed to provide the most comprehensive mapping between smartphone usage and well-being to date. Several important findings emerged. First, problematic smartphone usage showed moderate to strong negative correlations with measures of well-being. Second, using the phone to relax, escape, pass time, and be entertained (i.e., "entertainment usage") was negatively correlated with well-being, where, in contrast, using the phone habitually or for communication purposes was either unrelated or slightly positively related to well-being. Third, in the context of SWB, negative affect (+) followed by positive affect (-) had the strongest correlation with problematic smartphone usage, whereas satisfaction with life was relatively unrelated to problematic smartphone usage. Fourth, in the context of PWB, while all PWB scales correlated negatively with problematic smartphone usage, the largest negative correlations were seen for autonomy and environmental mastery, although notable correlations were seen for personal growth, purpose in life, and selfacceptance, and a somewhat weaker correlation for social relations.

\subsection{Smartphone Usage and Well-Being}

Correlations between smartphone usage and SWB varied across SWB dimensions. In contrast to all other measures of well-being, satisfaction with life was relatively unrelated to smartphone usage. In contrast to positive and negative affect, satisfaction with life is more of a cognitive evaluation of how a person appraises their life and how this relates to their expectations. It may be that such evaluations are more general and less related to daily hassles. In contrast, positive affect was negatively related to problematic smartphone usage, and negative affect was positively related to problematic smartphone usage. The relatively strong correlation for negative affect likely reflects the close relationship between negative affect and neuroticism. For example, Anglim and Grant (2016) report a .78 correlation between negative affect and trait neuroticism. Theory and research suggest that dispositional negative affect is one of the strongest predictors of problematic smartphone usage (e.g. Gao et al., 2017; Horwood \& Anglim, 2018; Pearson \& Hussain, 2015). Negative affect could be considered to be at the core of neuroticism, and in particular it captures the general tendency to view the environment negatively and engage in maladaptive coping strategies. Such a world view is likely to lead to more negative appraisal of smartphone usage and may even lead to compulsive smartphone usage behaviors.

The psychological well-being subscales most strongly associated with problematic smartphone usage were autonomy and environmental mastery followed by personal growth, purpose in life, self-acceptance, and social relations. Autonomy represents the degree to which a person's behavior is guided by their own internal standards, and the ability to resist social pressure to act or think a certain way (Ryff \& Keyes, 1995). Given that low autonomy is defined by greater concern for social approval, people with low autonomy may be more concerned with the apparent rewards offered by smartphone social media applications. Furthermore, the 
notification systems in smartphones may serve to reduce a person's sense of agency. In particular, while smartphones provide ways of configuring notification settings, this is often difficult. Many applications adopt an all-or-nothing policy where in order to be notified about something that might occasionally be important, the user is required to accept a barrage of largely irrelevant notifications. Equally, an application may persistently nag the user to enable notifications if they choose to disable them.

Similar to autonomy, environmental mastery describes behaviors that relate to having a sense of control over one's life, meeting one's own needs, and having mastery over the skills or abilities required to contribute to an individual's sense of purpose in life (Keyes, Shmotkin, \& Ryff, 2002a). One way to understand this relationship is to consider the time that is often devoted to habitual or entertainment usage. Users may feel that they have reduced control over their actions, including their ability to manage the challenges of daily life, as a result of an increasing drive for continuous connectivity and social feedback. Anecdotally, smartphone users often describe excessive usage as 'going down a rabbit hole', referring to a reduced awareness of the passage of time while immersed in online activity. The tendency to spend more time using a smartphone than intended has been found to cause problems in the lives of some users (Horwood \& Anglim, 2018). Similarly, excessive usage may lead individuals to have a sense that their time has not been well spent, and that other important aspects of daily life may have suffered as a result of time spent online.

It is worth noting that habitual smartphone usage was not strongly associated with PWB in the present study. This likely reflects the emphasis of the measure on automaticity. Instead, the entertainment usage scale reflects more of the mindless escapist-type usage, and this did correlate negatively with well-being. In general, experience leads to automaticity. With practice, people get quicker at performing tasks on their smartphone and they develop habits for when and how to use particular applications. This automaticity allows people to do things on their smartphone more effectively and frees up high-level cognitive resources. Thus, it seems that it is not habitual usage per se that is related to lower well-being. Rather it may be the mindless usage that is in some sense driven by the application interfaces and that people in some sense recognize as detracting from their own personal control.

Personal growth refers to continuous personal development and selfactualization, including a sense that one is engaged with and interested in life (Ryff \& Keyes, 1995). The negative relationship between personal growth and problematic smartphone usage could be understood as smartphone users having a sense that their usage is reducing the time they can devote to whatever things they feel are positive and healthy. Low personal growth scores reflect a person who feels their life has begun to stagnate, and has become bored or disinterested in life. Perhaps the negative correlation is reflecting an increased behavioral tendency of some users to spend large amounts of time engaging in sedentary, isolated, online browsing and passive entertainment at the expense of real-world personal engagements.

\subsection{Looking beyond associations}

Although the cross-sectional nature of the current study prevents causal inference, it is useful to consider the question of causality; that is, whether (a) smartphone usage causes changes in well-being, (b) well-being causes changes to smartphone usage, or (c) a third-variable explains the relationship. There are many 
reasons to assume that a person's dispositional well-being causes both actual and perceived problematic smartphone usages. In general, measures of well-being are highly stable over long periods of time. For example, Anglim, Weinberg, and Cummins (2015) obtained 7 year test-retest correlations for life satisfaction of $r=.76$ (see also the meta-analysis by Schimmack \& Oishi, 2005). A popular view supported by longitudinal research is that well-being is a homeostatic process whereby people fluctuate around a set-point (Cummins, Li, Wooden, \& Stokes, 2014; Headey \& Wearing, 1989; Headey \& Wearing, 1992). Evidence suggests that it takes truly major life events such as approaching death (Gerstorf et al., 2008), marital transition (Lucas, Clark, Georgellis, \& Diener, 2003), or acquiring a serious disability (Lucas, 2007) to substantially lower a person's well-being. And even in those cases, people will often adapt surprisingly quickly. From this perspective, people vary in their general dispositional tendency to view the world in more negative or positive ways. From a personality trait perspective, this is expressed particularly by neuroticism and extraversion (Anglim \& Grant, 2016) and from a well-being perspective this can be seen as a homeostatic set-point (Cummins, 2015). Whichever theoretical framework is adopted, people who are generally negative about their life may be more likely to be anxious about their smartphone usage, engage in compulsive habits, and create attachments that cause concerns. A person's well-being set-point may at least partly explain why two individuals with the same amount of smartphone usage do not necessarily both experience problems in their daily life that are associated with their type and level of smartphone usage.

However, the above dispositional explanation may not explain the relationship entirely. If smartphone usage influences well-being, it is important to consider which aspects of smartphone usage have positive influences and which have negative influences. Smartphones have integrated so many tools of daily life (e.g., torches, street directories, music players, cameras, etc.) that it is hard to not see these features as fundamentally useful. Only certain applications lead to intrusive notifications or encourage levels of usage that people may find impairs their daily functioning and disrupts social relationships. In a sense, the smartphone can become a form of automated escapism, where entertainment usage comes closest to a mindless form of usage. The negative relationship between usage of the smartphone for entertainment and wellbeing may be a reflection of emotional exhaustion, derived from the continuous stream of news and social feedback that smartphones facilitate. Alternatively, people may feel that this type of smartphone usage is typically not time well spent, and is failing to provide them with a sense of happiness or fulfilment that is associated with positive PWB. There is the notion that deeper personal fulfillment comes from satisfying more fundamental needs such as relating to others, achieving goals, and having purpose, an idea which appears to be borne out in the present data. Communication usage, that is, voice calls and SMS communication, was associated with an increase in PWB, presumably due to the positive experience of connecting directly with personally important others, rather than indirectly and somewhat impersonally through social media feeds. While some degree of mindless amusement has a place in many people's daily life (e.g. light entertainment on a daily commute), there seems to be a set of personality and wellbeing characteristics that may increase the likelihood that mindless usage is experienced as problematic. 


\subsection{Limitations and Future Research}

The current study had several limitations that should be noted. First, the research is cross-sectional, which prevents robust causal inference. Future research could employ longitudinal designs such as experience sampling to examine how realtime fluctuations in mood vary with smartphone usage. Randomized control trials could also be used to examine the efficacy of interventions that seek to assist people in regulating their smartphone usage. In particular, more research is needed to assess the effect of built-in and third-party software that is designed to manage notifications and set general and application-specific usage limits. For example, a recent study found that participants who took a week-long break from Facebook reported increased well-being (Tromholt, 2016). Second, both well-being and problematic smartphone usage were self-rated. It is likely that common appraisal processes influence how individuals evaluate their life and how they appraise their interactions with their smartphones. It would be interesting for future research to examine objective measures of smartphone usage.

\subsection{Conclusion}

The current study contributes to the overall understanding of the relationship between well-being and smartphone usage. By obtaining a large sample and using comprehensive full-scale measures of SWB and PWB, it provides a comprehensive mapping between these two constructs. A major contribution to the literature is the examination of relationships between smartphone usage and the six PWB scales used in Ryff's framework. Furthermore, the research furthers our understanding of the individual traits and characteristics that may play a role in the development of problematic smartphone usage. There may also be clinical applications for the present findings. There appear to be a set of personal characteristics, underpinned by a tendency to view the world in a generally negative way, that may put an individual at increased risk of developing problematic smartphone usage. Targeting smartphone usage as a modifiable behaviour may be a relatively straightforward means to help clients improve their overall wellbeing.

\section{References}

Alhassan, A. A., Alqadhib, E. M., Taha, N. W., Alahmari, R. A., Salam, M., \& Almutairi, A. F. (2018). The relationship between addiction to smartphone usage and depression among adults: a cross sectional study. BMC Psychiatry, $18,148$.

Anglim, J., \& Grant, S. (2016). Predicting psychological and subjective well-being from personality: Incremental prediction from 30 facets over the Big 5. Journal of Happiness Studies, 17, 59-80.

Anglim, J., Weinberg, M. K., \& Cummins, R. A. (2015). Bayesian hierarchical modeling of the temporal dynamics of subjective well-being: A 10 year longitudinal analysis. Journal of Research in Personality, 59, 1-14.

Arpaci, I., Baloğlu, M., Özteke Kozan, H. İ., \& Kesici, Ş. (2017). Individual Differences in the Relationship Between Attachment and Nomophobia Among College Students: The Mediating Role of Mindfulness. Journal Of Medical Internet Research, 19, e404-e404.

Ayyagari, R., Grover, V., \& Purvis, R. (2011). Technostress: technological antecedents and implications. MIS quarterly, 35, 831858.

Bianchi, A., \& Phillips, J. G. (2005). Psychological predictors of problem mobile phone use. CyberPsychology \& Behavior, 8 , 39-51.

Cao, X., Masood, A., Luqman, A., \& Ali, A. (2018). Excessive use of mobile social networking sites and poor academic performance: Antecedents and consequences from stressor-strain-outcome perspective. Computers in Human Behavior, 85, 163-174.

Chan, M. (2018). Mobile-mediated multimodal communications, relationship quality and subjective well-being: An analysis of smartphone use from a life course perspective. Computers in Human Behavior, 87, 254-262.

Chen, H.-T., \& Li, X. (2017). The contribution of mobile social media to social capital and psychological well-being: Examining the role of communicative use, friending and self-disclosure. Computers in Human Behavior, 75, 958-965. 
Chotpitayasunondh, V., \& Douglas, K. M. (2016). How "phubbing" becomes the norm: The antecedents and consequences of snubbing via smartphone. Computers in Human Behavior, 63, 9-18.

Cummins, R. A. (2015). The theory of subjective wellbeing homeostasis: A contribution to understanding life quality. In F. Maggino (Ed.), A Life Devoted to Quality of Life - Festschrift in Honor of Alex C. Michalos. Dordrecht, Netherlands: Springer.

Cummins, R. A., Li, L., Wooden, M., \& Stokes, M. (2014). A demonstration of set-points for subjective wellbeing. Journal of Happiness Studies, 15, 183-206.

David, M. E., Roberts, J. A., \& Christenson, B. (2018). Too Much of a Good Thing: Investigating the Association between Actual Smartphone Use and Individual Well-Being. International Journal of Human-Computer Interaction, 34, 265275.

Diener, E. (2009a). The science of well-being: The collected works of Ed Diener (Vol. 37): Springer Science \& Business Media.

Diener, E. (2009b). Subjective well-being The science of well-being (pp. 11-58): Springer.

Diener, E., Emmons, R. A., Larsen, R. J., \& Griffin, S. (1985). The satisfaction with life scale. Journal of personality assessment, 49, 71-75.

Diener, E., Lucas, R. E., \& Oishi, S. (2018). Advances and open questions in the science of subjective well-being. Collabra: Psychology, 4.

Diener, E., \& Ryan, K. (2009). Subjective Well-Being: A General Overview. South African Journal of Psychology, 39, $391-406$.

Diener, E., Wirtz, D., Tov, W., Kim-Prieto, C., Choi, D.-w., Oishi, S., \& Biswas-Diener, R. J. S. I. R. (2010). New Well-being Measures: Short Scales to Assess Flourishing and Positive and Negative Feelings. 97, 143-156.

Elhai, J. D., Levine, J. C., Dvorak, R. D., \& Hall, B. J. (2016). Fear of missing out, need for touch, anxiety and depression are related to problematic smartphone use. Computers in Human Behavior, 63, 509-516.

Elhai, J. D., Levine, J. C., Dvorak, R. D., \& Hall, B. J. (2017). Non-social features of smartphone use are most related to depression, anxiety and problematic smartphone use. Computers in Human Behavior, 69, 75-82.

Gao, T., Xiang, Y.-T., Zhang, H., Zhang, Z., \& Mei, S. (2017). Neuroticism and quality of life: Multiple mediating effects of smartphone addiction and depression. Psychiatry Research, 258, 457-461.

Gerstorf, D., Ram, N., Estabrook, R., Schupp, J., Wagner, G. G., \& Lindenberger, U. (2008). Life satisfaction shows terminal decline in old age: longitudinal evidence from the German Socio-Economic Panel Study (SOEP). Developmental Psychology, 44, 1148.

Han, S., Kim, K. J., \& Kim, J. H. (2017). Understanding Nomophobia: Structural Equation Modeling and Semantic Network Analysis of Smartphone Separation Anxiety. Cyberpsychology, Behavior And Social Networking, 20, 419-427.

Headey, B., \& Wearing, A. (1989). Personality, life events, and subjective well-being: toward a dynamic equilibrium model. Journal of personality and social psychology, 57, 731-739.

Headey, B., \& Wearing, A. J. (1992). Understanding happiness: A theory of subjective well-being. Melbourne: Longman Cheshire.

Horwood, S., \& Anglim, J. (2018). Personality and problematic smartphone use: A facet-level analysis using the Five Factor Model and HEXACO frameworks. Computers in Human Behavior.

Houben, M., Van Den Noortgate, W., \& Kuppens, P. (2015). The relation between short-term emotion dynamics and psychological well-being: A meta-analysis. Psychological Bulletin, 141, 901-930.

Hughes, N., \& Burke, J. (2018). Sleeping with the frenemy: How restricting 'bedroom use' of smartphones impacts happiness and wellbeing. Computers in Human Behavior, 85, 236-244.

Hussain, Z., Griffiths, M. D., \& Sheffield, D. (2017). An investigation into problematic smartphone use: The role of narcissism, anxiety, and personality factors. Journal Of Behavioral Addictions, 6, 378-386.

Kayiş, A. R., Satici, S. A., Yilmaz, M. F., Şimşek, D., Ceyhan, E., \& Bakioğlu, F. (2016). Big five-personality trait and internet addiction: A meta-analytic review. Computers in Human Behavior, 63, 35-40.

Keyes, C. L., Shmotkin, D., \& Ryff, C. D. (2002a). Optimizing well-being: The empirical encounter of two traditions. Journal of personality and social psychology, 82, 1007-1022.

Keyes, C. L. M., Shmotkin, D., \& Ryff, C. D. (2002b). Optimizing well-being: The empirical encounter of two traditions. Journal of personality and social psychology, 82, 1007-1022.

Kim, E., \& Koh, E. (2018). Avoidant attachment and smartphone addiction in college students: The mediating effects of anxiety and self-esteem. Computers in Human Behavior, 84, 264-271.

Kim, E. Y., Joo, S. W., Han, S. J., Kim, M. J., \& Choi, S. Y. (2018). Depression, Impulse Control Disorder, and Life Style According to Smartphone Addiction...The 16 World Congress of Medical and Health Informatics: Precision Healthcare Through Informatics (MedInfo2017) was held in Hangzhou, China from August 21st to 25th, 2017. Studies in Health Technology \& Informatics, 245, 1272-1272.

Kim, H., Min, J., Min, K., Lee, T., \& Yoo, S. (2018). Relationship among family environment, self-control, friendship quality, and adolescents' smartphone addiction in South Korea: Findings from nationwide data. PloS One, 13, e 0190896e0190896.

Kim, Y.-J., Jang, H. M., Lee, Y., Lee, D., \& Kim, D.-J. (2018). Effects of Internet and Smartphone Addictions on Depression and Anxiety Based on Propensity Score Matching Analysis. International journal of environmental research and public health, 15 .

Kuang-Tsan, C., \& Fu-Yuan, H. (2017). Study on Relationship Among University Students' Life Stress, Smart Mobile Phone Addiction, and Life Satisfaction. Journal of Adult Development, 24, 109-118. 
Kumcagiz, H., \& Gündüz, Y. (2016). Relationship between Psychological Well-Being and Smartphone Addiction of University Students. International Journal of Higher Education, 5, 144-156.

Lapierre, M. A., \& Lewis, M. N. (2016). Should It Stay or Should It Go Now? Smartphones and Relational Health. Psychology of Popular Media Culture.

Lee, Y.-K., Chang, C.-T., Lin, Y., \& Cheng, Z.-H. (2014). The dark side of smartphone usage: Psychological traits, compulsive behavior and technostress. Computers in Human Behavior, 31, 373-383.

Li, J., Lepp, A., \& Barkley, J. E. (2015). Locus of control and cell phone use: Implications for sleep quality, academic performance, and subjective well-being. Computers in Human Behavior, 52, 450-457.

Lucas, R. E. (2007). Long-term disability is associated with lasting changes in subjective well-being: evidence from two nationally representative longitudinal studies. Journal of personality and social psychology, 92, 717-730.

Lucas, R. E., Clark, A. E., Georgellis, Y., \& Diener, E. (2003). Reexamining adaptation and the set point model of happiness: reactions to changes in marital status. Journal of personality and social psychology, 84, 527-539.

Maier, C., Laumer, S., Weinert, C., \& Weitzel, T. (2015). The effects of technostress and switching stress on discontinued use of social networking services: a study of Facebook use. Information Systems Journal, 25, 275-308.

Park, N., \& Lee, H. (2012). Social implications of smartphone use: Korean college students' smartphone use and psychological well-being. Cyberpsychology, Behavior, and Social Networking, 15, 491-497.

Pearson, C., \& Hussain, Z. (2015). Smartphone Use, Addiction, Narcissism, and Personality: A Mixed Methods Investigation. International Journal of Cyber Behavior, Psychology and Learning (IJCBPL), 5, 17-32.

Ragu-Nathan, T., Tarafdar, M., Ragu-Nathan, B. S., \& Tu, Q. (2008). The consequences of technostress for end users in organizations: Conceptual development and empirical validation. Information systems research, 19, 417-433.

Rotondi, V., Stanca, L., \& Tomasuolo, M. (2017). Connecting alone: Smartphone use, quality of social interactions and wellbeing. Journal of Economic Psychology, 63, 17-26.

Ryan, R. M., \& Deci, E. L. (2001). On happiness and human potentials: A review of research on hedonic and eudaimonic wellbeing. Annual review of psychology, 52, 141-166.

Ryff, C. D. (1989). Happiness is everything, or is it? Explorations on the meaning of psychological well-being. Journal of Personality and Social Psychology, 57, 1069-1081.

Ryff, C. D., \& Keyes, C. L. M. (1995). The structure of psychological well-being revisited. Journal of Personality and Social Psychology, 69, 719-727.

Samaha, M., \& Hawi, N. S. (2016). Relationships among smartphone addiction, stress, academic performance, and satisfaction with life. Computers in Human Behavior, 57, 321-325.

Schimmack, U., \& Oishi, S. (2005). The influence of chronically and temporarily accessible information on life satisfaction judgments. Journal of personality and social psychology, 89, 395-406.

Tarafdar, M. (2017). The technostress trifecta- techno eustress, techno-distress, and design: an agenda for research.

Tarafdar, M., Tu, Q., Ragu-Nathan, B. S., \& Ragu-Nathan, T. (2007). The impact of technostress on role stress and productivity. Journal of Management Information Systems, 24, 301-328.

Toda, M., Ezoe, S., Mure, K., \& Takeshita, T. (2016). Relationship of smartphone dependence to general health status and personality traits among university students. Open Journal of Preventive Medicine, 6, 215.

Tov, W., \& Diener, E. (2013). Subjective well-being.

Tromholt, M. (2016). The Facebook Experiment: Quitting Facebook Leads to Higher Levels of Well-Being. Cyberpsychology, Behavior And Social Networking, 19, 661-666.

Van Deursen, A., Bolle, C. L., Hegner, S. M., \& Kommers, P. A. (2015). Modeling habitual and addictive smartphone behavior: The role of smartphone usage types, emotional intelligence, social stress, self-regulation, age, and gender. Computers in Human Behavior, 45, 411-420.

Watson, D., Clark, L. A., \& Tellegen, A. (1988). Development and validation of brief measures of positive and negative affect: the PANAS scales. Journal of personality and social psychology, 54, 1063-1070. 


\section{Table 1}

Descriptive Statistics, Cronbach's Alpha and Intercorrelations for Well-Being, Smartphone Usage and Demographic Variables

\begin{tabular}{|c|c|c|c|c|c|c|c|c|c|c|c|c|c|c|c|c|c|c|c|}
\hline Variable & $\mathrm{M}$ & SD & skew & kurtosis & alpha & 1 & 2 & 3 & 4 & 5 & 6 & 7 & 8 & 9 & 10 & 11 & 12 & 13 & 14 \\
\hline \multicolumn{20}{|l|}{ SWB } \\
\hline 1. Satisfaction with life & 4.71 & 1.34 & -0.57 & -0.38 & .86 & & & & & & & & & & & & & & \\
\hline 2. Positive affect & 3.31 & 0.77 & -0.39 & -0.32 & .89 & .53 & & & & & & & & & & & & & \\
\hline 3. Negative affect & 2.06 & 0.75 & 1.03 & 0.73 & .88 & -.45 & -.41 & & & & & & & & & & & & \\
\hline \multicolumn{20}{|l|}{ PWB } \\
\hline 4. Positive relations & 4.56 & 0.87 & -0.50 & -0.24 & .89 & .50 & .52 & -.45 & & & & & & & & & & & \\
\hline 5. Autonomy & 4.18 & 0.78 & -0.14 & -0.21 & .86 & .23 & .28 & -.45 & .28 & & & & & & & & & & \\
\hline 6. Environmental mastery & 4.18 & 0.83 & -0.37 & -0.16 & .88 & 61 & .59 & -.61 & .60 & .47 & & & & & & & & & \\
\hline 7. Personal growth & 4.96 & 0.65 & -0.93 & 1.15 & .86 & 40 & .52 & -.41 & .57 & .44 & .60 & & & & & & & & \\
\hline 8. Purpose in life & 4.55 & 0.85 & -0.62 & 0.07 & .90 & .58 & .59 & -.52 & .54 & .42 & .76 & .71 & & & & & & & \\
\hline 9. Self-acceptance & 4.17 & 1.02 & -0.54 & -0.35 & .93 & .75 & .62 & -.60 & .61 & .48 & .78 & .62 & .77 & & & & & & \\
\hline \multicolumn{20}{|l|}{ Smartphone usage } \\
\hline 10. Habitual usage & 4.07 & 0.75 & -1.06 & 1.80 & .89 & .10 & -.01 & .15 & .03 & -.22 & -.05 & .07 & .03 & .01 & & & & & \\
\hline 11. Entertainment usage & 3.60 & 0.76 & -0.86 & 1.45 & .83 & -.06 & -.13 & .26 & -.11 & -.31 & -.21 & -.15 & -.14 & -.18 & .65 & & & & \\
\hline 12. Communication usage & 4.27 & 0.65 & -1.38 & 3.53 & .77 & .09 & .14 & .00 & .27 & -.11 & .10 & .15 & .13 & .06 & .51 & .44 & & & \\
\hline 13. Problematic usage & 2.45 & 0.73 & 0.12 & -0.31 & .91 & -.06 & -.19 & .31 & -.15 & -.39 & -.30 & -.23 & -.21 & -.20 & .58 & .64 & .31 & & \\
\hline \multicolumn{20}{|l|}{ Demographics } \\
\hline 14. Female & 0.79 & 0.40 & & & & .11 & .02 & .06 & .09 & -.06 & .02 & .14 & .13 & .07 & .13 & .12 & .14 & .12 & \\
\hline 15. Age (years) & 25.13 & 7.80 & & & & .01 & .07 & -.17 & .11 & .26 & .22 & .22 & .21 & .16 & -.26 & -.31 & -.22 & -.27 & .01 \\
\hline
\end{tabular}

Note. Correlations greater than or equal to $.09, .12$, and .15 are statistically significant at $.05, .01$, and .001 respectively. Absolute cross-correlations between smartphone usage and well-being variables greater than or equal to .20 are bolded. $\mathrm{SWB}=$ Subjective well-being, $\mathrm{PWB}=$ Psychological well-being. Female is coded $0=$ Male, $1=$ Female.

Table 2

Regression Models Predicting Well-Being from Demographics and Smartphone Usage

\begin{tabular}{lccccccccc}
\hline & SWL & PA & NA & PR & AU & EM & PG & PL & SA \\
\hline Standardized Beta & & & & & & & & & \\
$\quad$ Female & $.11^{*}$ & .02 & .04 & .07 & -.03 & .02 & $.13^{*}$ & $.12^{*}$ & .08 \\
Age & .00 & .04 & $-.10^{*}$ & $.10^{*}$ & $.17^{*}$ & $.18^{*}$ & $.20^{*}$ & $.18^{*}$ & $.12^{*}$ \\
Habitual usage & $.22^{*}$ & $.12^{*}$ & -.07 & .08 & .07 & $.18^{*}$ & $.31^{*}$ & $.23^{*}$ & $.24^{*}$ \\
Entertainment usage & $-.19^{*}$ & $-.15^{*}$ & $.16^{*}$ & $-.21^{*}$ & -.11 & $-.16^{*}$ & $-.20^{*}$ & $-.17^{*}$ & $-.22^{*}$ \\
Communication usage & .08 & $.23^{*}$ & $-.15^{*}$ & $.39^{*}$ & .05 & $.22^{*}$ & $.20^{*}$ & $.19^{*}$ & $.12^{*}$ \\
Problematic usage & -.10 & $-.23^{*}$ & $.26^{*}$ & $-.16^{*}$ & $-.33^{*}$ & $-.32^{*}$ & $-.31^{*}$ & $-.26^{*}$ & $-.20^{*}$ \\
& & & & & & & & & \\
Adjusted r-squared & $.05^{*}$ & $.09^{*}$ & $.13^{*}$ & $.16^{*}$ & $.18^{*}$ & $.17^{*}$ & $.21^{*}$ & $.16^{*}$ & $.10^{*}$ \\
\hline
\end{tabular}

Note. $\mathrm{SWL}=$ satisfaction with life, $\mathrm{PA}=$ positive affect, $\mathrm{NA}=$ negative affect, $\mathrm{PR}=$ positive relations, $\mathrm{AU}=$ autonomy, $\mathrm{EM}=$ environmental mastery, $\mathrm{PG}=$ personal growth, $\mathrm{PL}=$ purpose in life, $\mathrm{SA}=$ self-acceptance

$* p<.05$ 